ARTICLE

https://doi.org/10.1038/s41467-021-26038-9

\title{
Urban mining by flash Joule heating
}

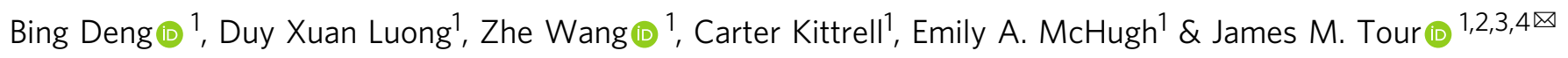

Precious metal recovery from electronic waste, termed urban mining, is important for a circular economy. Present methods for urban mining, mainly smelting and leaching, suffer from lengthy purification processes and negative environmental impacts. Here, a solvent-free and sustainable process by flash Joule heating is disclosed to recover precious metals and remove hazardous heavy metals in electronic waste within one second. The sample temperature ramps to $\sim 3400 \mathrm{~K}$ in milliseconds by the ultrafast electrical thermal process. Such a high temperature enables the evaporative separation of precious metals from the supporting matrices, with the recovery yields $>80 \%$ for $\mathrm{Rh}, \mathrm{Pd}, \mathrm{Ag}$, and $>60 \%$ for $\mathrm{Au}$. The heavy metals in electronic waste, some of which are highly toxic including $\mathrm{Cr}, \mathrm{As}, \mathrm{Cd}, \mathrm{Hg}$, and $\mathrm{Pb}$, are also removed, leaving a final waste with minimal metal content, acceptable even for agriculture soil levels. Urban mining by flash Joule heating would be $80 \times$ to $500 \times$ less energy consumptive than using traditional smelting furnaces for metal-component recovery and more environmentally friendly.

\footnotetext{
${ }^{1}$ Department of Chemistry, Rice University, Houston, TX 77005, USA. ${ }^{2}$ Smalley-Curl Institute, Rice University, Houston, TX 77005, USA. ${ }^{3}$ NanoCarbon Center and the Welch Institute for Advanced Materials, Rice University, Houston, TX 77005, USA. ${ }^{\circ}$ Department of Materials Science and NanoEngineering,

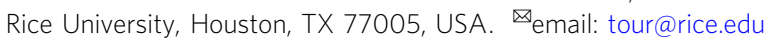


$\mathrm{M}$ ore than 40 million tons of electronic waste (e-waste) are produced globally each year ${ }^{1,2}$, which is the fastestgrowing component of solid wastes due to the rapid upgrade of personal electrical and electronic equipments $\mathrm{s}^{3,4}$. Most e-waste is landfilled with only $\sim 20 \%$ being recycled ${ }^{5}$, which could lead to negative environmental impact due to the broad use of heavy metals in electronics ${ }^{6-8}$. E-waste could become a sustainable resource because it contains abundant valuable metals ${ }^{9}$. The concentrations of some precious metals in e-waste are higher than those in ores ${ }^{1}$. Precious metals recovery from e-waste, termed urban mining, is becoming more cost-effective than virgin mining ${ }^{2}$ and important for a circular economy ${ }^{8}$. Similarly, due to the broad use of heavy metals in electronics, including $\mathrm{Cd}, \mathrm{Co}$, $\mathrm{Cu}, \mathrm{Ni}, \mathrm{Pb}$, and $\mathrm{Zn}$, e-waste could lead to significant health risks and negative environmental impact ${ }^{6-8}$. The heavy metal leakage due to improper landfill disposal leads to environmental disruption ${ }^{1,8}$. The release of hazardous components during the recycling processes in the form of dust or smoke ${ }^{6}$ deteriorates the health of recycling workers and local residents. For example, a significantly higher concentration of $\mathrm{Pb}$ has been found in the blood of e-waste workers ${ }^{7,10}$.

The lack of high-yielding and environmentally friendly recovery processes are the main obstacles to urban mining 9 . The traditional method for e-waste recycling is based on a pyrometallurgy process $^{11}$, where metals are melted by heating at high temperature. Pyrometallurgy is energy-intensive, lacks selectivity, and requires high-grade precursors ${ }^{12}$. Pyrometallurgical processes also produce hazardous fumes containing heavy metals, especially for those with low melting points such as $\mathrm{Hg}, \mathrm{Cd}$, and $\mathrm{Pb}^{9}$. The hydrometallurgical process is more selective and done by leaching the metals using acid, base, or cyanide ${ }^{13}$. The leaching kinetics are usually slow. The use of highly concentrated leaching agents renders the hydrometallurgical process difficult for large-scale applications, and large amounts of liquid waste and sludge are produced that could result in secondary pollution ${ }^{14}$. Biometallurgy could be highly selective and environmentally sustainable, yet it is still in its infancy ${ }^{15}$. The separation of valuable metals from various materials matrices, including plastics, glass, and ceramics, are based upon their differences in physical or chemical properties. For example, the gravity separation technique relies on differing specific densities ${ }^{16}$. Magnetic separation is used to separate magnetic metals from nonferrous waste ${ }^{17}$. Hydrometallurgical separation is based upon the chemical reactivity of metals with leaching agents ${ }^{18}$.

Here, we show that the different vapor pressure of metals compared to that of substrate materials (carbon, ceramics, and glass) enables the separation of metals from e-waste. This is termed evaporative separation. The high vapor pressure of precious metals is obtained by an ultrafast flash Joule heating (FJH) process under vacuum. A subsecond current pulse is passed through the precursors, which brings the sample to an ultrahigh temperature of $\sim 3400 \mathrm{~K}$, enabling the evaporative separation of precious metals. Halide additives are used to improve the recovery yield to $>80 \%$ for $\mathrm{Rh}, \mathrm{Pd}$, and $\mathrm{Ag}$, and $>60 \%$ for $\mathrm{Au}$ that are abundant in the tested e-waste. Alternatively, compared with directly leaching e-waste raw materials, by leaching the residual solids after $\mathrm{FJH}$, the recovery yield is significantly improved with tens of times increase for $\mathrm{Ag}$ and few times increase for $\mathrm{Rh}, \mathrm{Pd}$, and $\mathrm{Au}$. The toxic heavy metals, including $\mathrm{Cd}, \mathrm{Hg}, \mathrm{As}, \mathrm{Pb}$, and $\mathrm{Cr}$, could also be removed and collected, minimizing the health risks and environmental impact of the recycling process.

\section{Results}

Evaporative separation of precious metals from e-waste by FJH. The FJH process to recover precious metals from e-waste involves three stages (Fig. 1a). The metals in e-waste were heated and evaporated by ultrahigh-temperature $\mathrm{FJH}$, then the metal vapors were transported under vacuum and collected by condensation. A printed circuit board (PCB) from a discarded computer, a representative e-waste, was used as the starting material (Fig. 1b and Supplementary Fig. 1). The PCB was ground to small powder and mixed with carbon black (CB), which served as the conductive additive (Fig. 1b, inset). To establish baseline concentrations, the PCB was digested using dilute aqua regia ${ }^{19}$, and the concentration of precious metals was determined by inductively coupled plasma mass spectrometry (ICP-MS). Among the precious metals, $\mathrm{Rh}, \mathrm{Pd}, \mathrm{Ag}$, and $\mathrm{Au}$ are abundant with concentrations of several to tens of parts per million (ppm) (Fig. 1c).

In a typical FJH process, the mixture of $\mathrm{PCB}$ powder and $\sim 30 \mathrm{wt} \% \mathrm{CB}$ was slightly compressed inside a quartz tube between two sealed electrodes (Fig. 1a and Supplementary Fig. 2). One electrode was a porous $\mathrm{Cu}$ electrode to facilitate gas diffusion, and the other was a graphite rod (Supplementary Fig. 3). The resistance of the sample was tunable by adjusting the compressive force on the two electrodes. The two electrodes were connected to a capacitor bank with a total capacitance of $60 \mathrm{mF}$ (Supplementary Fig. 3). The detailed separation conditions are shown in Supplementary Table 1 . The high-voltage discharge of the capacitor bank brings the reactant to a high temperature. With the fixed sample resistance of $\sim 1 \Omega$, the current passing through the sample was measured under different FJH voltages (Fig. 1d). The real-time temperature of the sample was estimated by fitting the blackbody radiation in the 600-1100 $\mathrm{nm}$ emission (Supplementary Fig. 4). The temperature varied according to the $\mathrm{FJH}$ voltage, reaching $\sim 3400 \mathrm{~K}$ at $150 \mathrm{~V}$ in $<50 \mathrm{~ms}$ (Fig. 1e). Since the resistance of the sample is much larger than that of the graphite and porous $\mathrm{Cu}$ electrode, the voltage drop was mainly imposed on the sample. Hence, the high-temperature region was limited to the sample and the FJH setup has good durability even though it can achieve a high temperature of $>3000 \mathrm{~K}$ (Supplementary Fig. 5). Numerical simulations showed that the temperature was relatively uniform along both the longitudinal and radial directions of the sample (Supplementary Note 1, temperature simulation, Supplementary Fig. 6), demonstrating the homogenous heating ability of the $\mathrm{FJH}$ process.

Such a high temperature $(>3000 \mathrm{~K})$ volatilizes most of the noncarbon components. According to the calculated vapor pressure-temperature relationships (Fig. 1f), the precious metals have a higher vapor pressure than carbon, the latter not subliming until $\sim 3900 \mathrm{~K}^{20}$. As a result, the metals are evaporated, and the major carbon-containing components such as plastics were carbonized $^{21,22}$. The evaporated metal vapors were captured by condensation in a cold trap (Fig. 1a and Supplementary Fig. 2). Some of the vapor remained gaseous even at the liquid $\mathrm{N}_{2}$ temperature (77 K) (Supplementary Fig. 2); these gases were presumed to be $\mathrm{H}_{2}$ and $\mathrm{CO}^{22}$. The content of the precious metals in the condensed solid was measured and the recovery yield was calculated (Fig. 1g and Supplementary Note 2). The recovery yield of $\mathrm{Ag}$ was $\sim 40 \%$, while $\mathrm{Rh}, \mathrm{Pd}$, and Au had a relatively low recovery yield of $\sim 3 \%$. This is because $\mathrm{Ag}$ has a high vapor pressure and relatively low boiling point (Supplementary Fig. 7). The concentration of precious metals in the starting commercial CB is $1-2 \%$ of the concentration in $\mathrm{PCB}$, hence their presence in $\mathrm{CB}$ will not introduce significant errors (Supplementary Fig. 8). Moreover, the precious metals tend to not form stable carbide phases even at high temperature due to their extremely low C solubility ${ }^{23}$ (Supplementary Fig. 9). Hence, the use of $\mathrm{CB}$ as a conductive additive will not affect the evaporative behavior of precious metals.

Halide assisted improvement of recovery yield. The highrecovery yield of the evaporative separation relies on the 

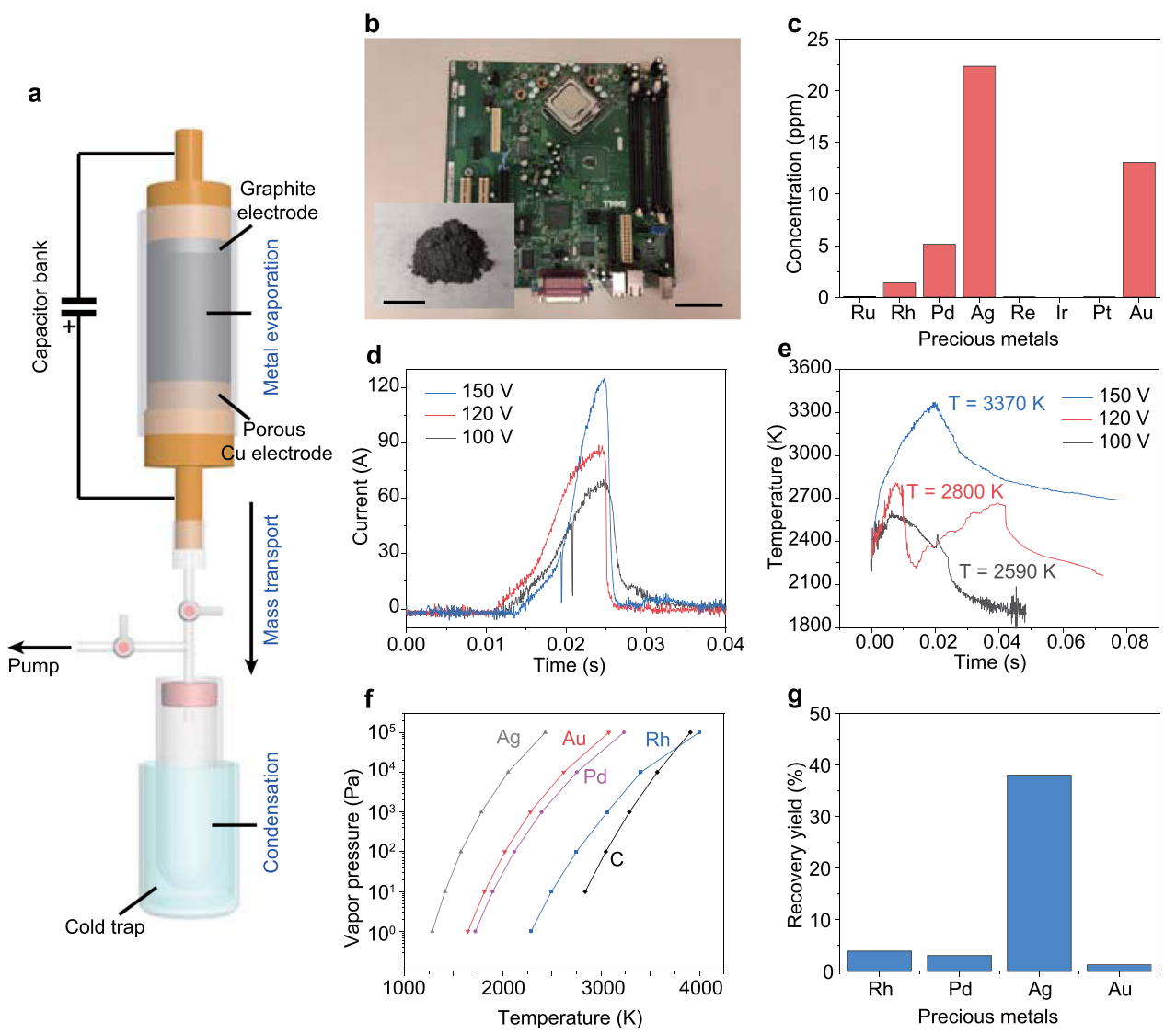

Fig. 1 Recovery of precious metals by flash Joule heating (FJH). a Schematic of the FJH and evaporative separation system. The system was composed of three parts, including FJH for metal evaporation, the vacuum system for mass transport, and the cold trap for volatiles condensation. $\mathbf{b}$ Picture of a printed circuit board (PCB). Scale bar, $5 \mathrm{~cm}$. Inset, the mixture of carbon black (CB) with PCB powder. Scale bar, $2 \mathrm{~cm}$. c Concentrations of precious metals in PCB as determined by inductively coupled plasma mass spectrometry (ICP-MS). d Currents vs time recorded under different FJH voltages. e Real-time temperature measurements at different FJH voltages by fitting blackbody radiation emitted from the sample. $\mathbf{f}$ Vapor pressure-temperature relationship of precious metals and carbon. $\mathbf{g}$ Recovery yield of precious metals by condensing the evaporated gas components. The recovery yield is the average of three independent FJH experiments $(n=3)$.

generation of more volatile components. To improve the recovery, halides were used as additives because of the much higher vapor pressure of metal halides compared with the elemental metals (Supplementary Fig. 10) ${ }^{24}$. Fluorine-containing components were first used as the additive, including sodium fluoride $(\mathrm{NaF})$ and polytetrafluoroethylene (PTFE, Teflon). With the additives, the recovery yields of $\mathrm{Rh}$ and $\mathrm{Pd}$ were improved to $>80 \%$ and $70 \%$, respectively (Fig. 2a, b and Supplementary Note 2), demonstrating $\sim 20 \times$ improvement compared to the experiments without additives. The concentration of precious metals in the additives was $<2 \%$ of those in PCB (Supplementary Fig. 11), hence we can exclude the additives from introducing significant error in the recovery of precious metals. Chlorinecontaining compounds were tried because of their abundance and low cost. Both sodium chloride $(\mathrm{NaCl})$ and potassium chloride $(\mathrm{KCl})$ were used (Fig. 2c and Supplementary Fig. 12). The recovery yields of $\mathrm{Rh}, \mathrm{Pd}$, and $\mathrm{Ag}$ increased for both $\mathrm{NaCl}$ and $\mathrm{KCl}$ additives. In addition, both polyvinyl chloride (PVC) and chlorinated polyvinyl chloride (CPVC) plastics were used (Fig. 2d and Supplementary Fig. 12). The recovery yield of all four precious metals was increased, especially for Ag, with the recovery yield improving to $>80 \%$. The plastic additives were ground postconsumer samples with very low or negative values, so they will not introduce significant materials cost during the e-waste recycling process.
Even with the $\mathrm{F}$ and $\mathrm{Cl}$ additives, the recovery yield of $\mathrm{Au}$ is $<10 \%$. Interestingly, the recovery yields of all four precious metals were improved when sodium iodide $(\mathrm{NaI})$ was used as the additive; the recovery yield of Au was improved to $>60 \%$ (Fig. 2e). The I additive has the best performance among halides for $\mathrm{Au}$ recovery. According to the hard and soft acids and bases (HSAB) theory, $\mathrm{Au}^{+}$is a soft Lewis acid, and $\mathrm{I}^{-}$is a soft Lewis base while $\mathrm{F}^{-}$and $\mathrm{Cl}^{-}$are harder than $\mathrm{I}^{-25}$, favoring AuI. By using an additive mixture of $\mathrm{NaF}, \mathrm{NaCl}$, and $\mathrm{NaI}$, the precious metals all had a good recovery yield, $>60 \%$ for $\mathrm{Rh},>60 \%$ for $\mathrm{Pd},>80 \%$ for $\mathrm{Ag}$, and $>40 \%$ for Au (Fig. 2f). The composition analysis of the raw materials and the remaining solid after FJH by X-ray photoemission spectroscopy (XPS) showed that $10-40 \%$ of the halide additives were evaporated during the $\mathrm{FJH}$ process (Supplementary Fig. 13), which could be recovered and reused by a water washing and precipitation process.

We conducted a total composition analysis of the collected metals in the cold trap (Supplementary Note 3). In both cases with or without the chemical additives, in addition to the precious metals, the most abundant metals were $\mathrm{Cu}$ with mass ratio $>60 \mathrm{wt}$ $\%$, followed by other prominent metals in e-waste including $\mathrm{Al}$, $\mathrm{Sn}, \mathrm{Fe}$, and Zn (Supplementary Fig. 14). Further purification and refining could be done by selective precipitation, solvent extraction, and solid-phase extraction, which are commercially well-established practices ${ }^{26}$. 
a

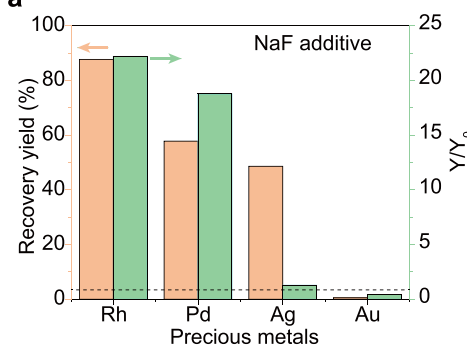

d

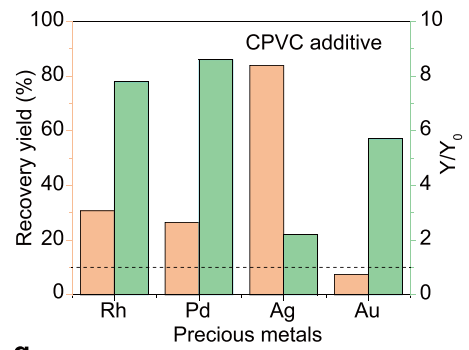

b

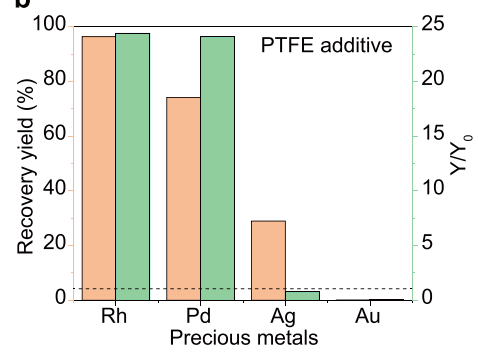

e

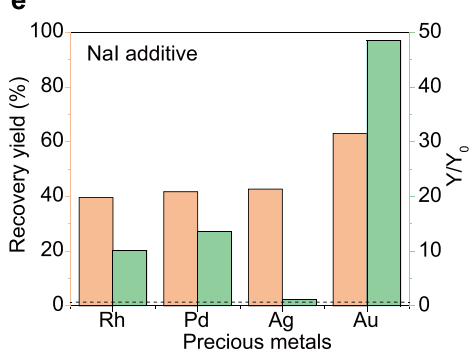

c

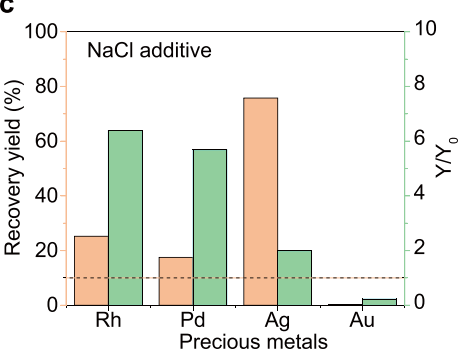

f

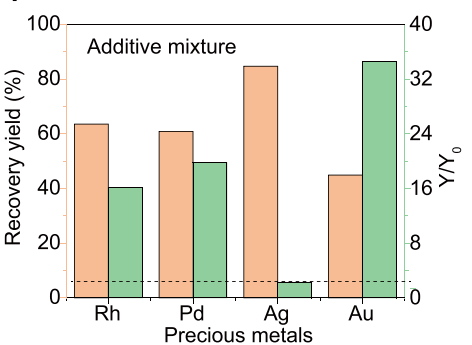

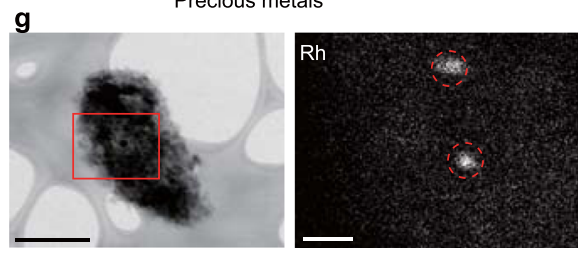
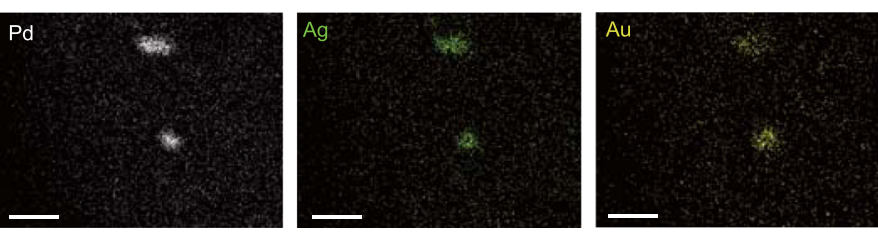

Fig. 2 Halide assisted improvement of recovery yield. Recovery yield of precious metals by using (a) NaF, (b) PTFE, (c) NaCl, (d) CPVC, (e) Nal, and (f) mixture of $\mathrm{NaF}, \mathrm{NaCl}$, and $\mathrm{Nal}$, as additives. $Y_{\mathrm{O}}$ and $Y$ mean the recovery yield of precious metals without and with additives, respectively. The dashed line denotes $Y / Y_{0}=1$, meaning that there is no advantage of the additive if $Y / Y_{0} \leq 1$. The recovery yields were the average of three independent flash Joule heating $(\mathrm{FJH})$ experiments $(n=3)$. $\mathbf{g}$ Scanning transmission electron microscopy (STEM) image of the collected solids, and energy dispersive spectroscopy (EDS) maps of Rh, Pd, Ag, and Au at the rectangular region. Scale bar in STEM image, $0.5 \mu$ m; scale bars in EDS maps, 100 nm. The dashed circles in Rh show the clustered alloys.

The morphology and chemical composition of the condensed solids were characterized using scanning transmission electron microscopy (STEM) and energy dispersion spectroscopy (EDS). The elemental maps showed the clustered alloy particles of $\mathrm{Rh}$, $\mathrm{Pd}, \mathrm{Ag}$, and $\mathrm{Au}$ (Fig. 2g), which were formed by the ultrafast heating and rapid cooling of the FJH process. This is similar to the case of the carbothermic shock synthesis of high-entropy alloy nanoparticles, which could be potentially used in catalysts ${ }^{27}$. In other regions, the precious metals spreading over the entire product were also observed (Supplementary Fig. 15). Moreover, the XPS analysis of the collected volatiles showed that Ag and Au were mainly in the elemental state, while elemental state and higher oxidation state coexisted for $\mathrm{Rh}$ and $\mathrm{Pd}$, presumably due to their different chemical reactivity (Supplementary Note 3 and Supplementary Fig. 16).

Improved leaching efficiency of precious metals by FJH. Apart from the condensation of the volatile composition, the other pathway to recover the precious metals was by leaching the residual solids obtained by FJH (Supplementary Fig. 17a). Different from the use of a vacuum to facilitate the metal volatilization in the evaporative separation scheme (Fig. 1a), a pressurized setup was built to trap the metals in the reactor (Fig. 3a). An inert gas $\left(\mathrm{N}_{2}\right)$ cylinder was connected to the $\mathrm{FJH}$ reactor, where the pressure was monitored by a pressure gauge. The inner pressure $\left(P_{0}\right)$ during $\mathrm{FJH}$ was estimated to be $\sim 5 \mathrm{~atm}$ according to the amount of collected gas (Supplementary Fig. 2 and Supplementary Note 1). Based on the pressure drop and the size of the FJH chamber, the gas diffusion was simulated under different pressures $\left(P_{\text {out }}\right)$ (Fig. 3b, Supplementary Fig. 18). When vacuum was used $\left(P_{\text {out }}=0 \mathrm{~atm}\right)$, as it is in the evaporative separation (Fig. 1a), the gas velocity was up to $800 \mathrm{~m} \mathrm{~s}^{-1}$. Such a high gas velocity aided the volatile components to quickly diffuse to the cold trap and prevent the condensation loss at the tube sidewalls. In contrast, the gas velocity was greatly reduced with the increase in pressure (Fig. 3b). As a result, more of the originally volatile components were trapped within the residual solids in the reactor. The detailed reaction conditions for the pressurized FJH are shown in Supplementary Table 2.

We started from leaching the residual solids after FJH (denoted as PCB-Flash) at $120 \mathrm{~V}$ and atmospheric pressure using dilute acids $\left(1 \mathrm{M} \mathrm{HCl}, 1 \mathrm{M} \mathrm{HNO}_{3}\right.$ ) (Supplementary Fig. 17a). The leachable content of $\mathrm{Rh}, \mathrm{Pd}$, and $\mathrm{Ag}$ in $\mathrm{PCB}$-Flash was substantially higher than that in the PCB raw materials (Fig. 3c). The ratio of the recovery yield by leaching the PCB-Flash $(Y)$ and leaching the PCB raw materials $\left(Y_{0}\right)$ was calculated. FJH with leaching was far more effective than leaching alone. The recovery yield of $\mathrm{Rh}, \mathrm{Pd}$, and $\mathrm{Ag}$ was increased by $4.17 \pm 0.48,2.90 \pm 0.31$, $56.0 \pm 18.1$ times, respectively (Fig. $3 \mathrm{c}$ ). The deviations could be from the inhomogeneous distribution of precious metals in e-waste. Interestingly, the Au recovery yield was reduced after the FJH process. The reason was presumably the formation of covalent bonds between $\mathrm{Au}$ and carbon ${ }^{28}$, which could significantly increase the difficulty of acid leaching. The thermogravimetric analysis (TGA) of the PCB-Flash showed that the carbon could be removed in the air at $\sim 700{ }^{\circ} \mathrm{C}$ (Supplementary Fig. 17b). Hence, the PCB-Flash solid was calcined at $700^{\circ} \mathrm{C}$ for $1 \mathrm{~h}$ (denoted as PCB-Flash-Calcination, Supplementary 
a

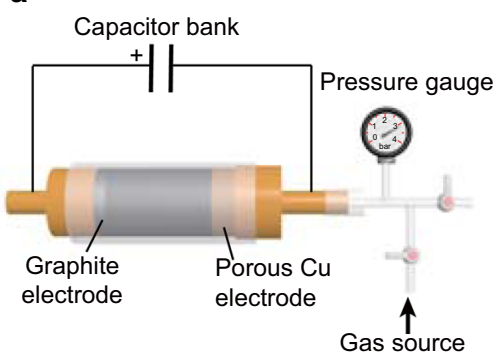

C

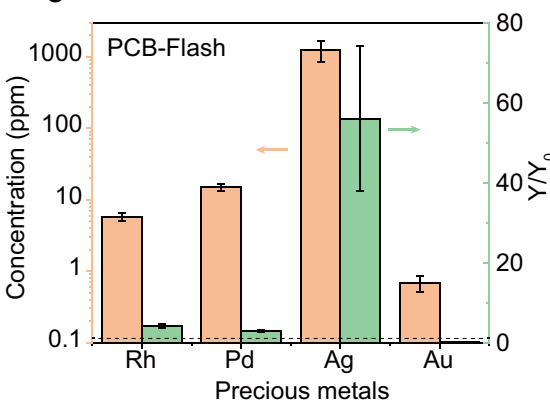

e

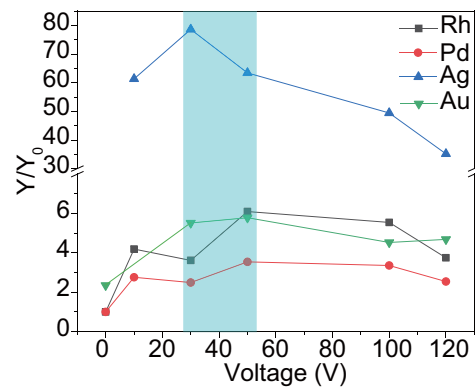

b

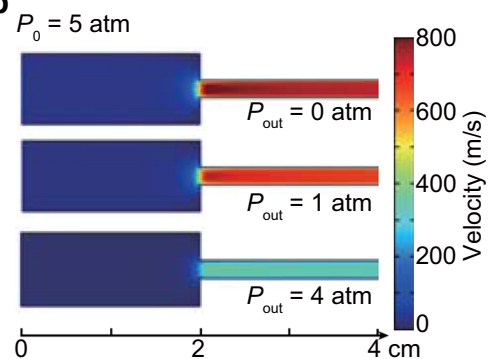

d

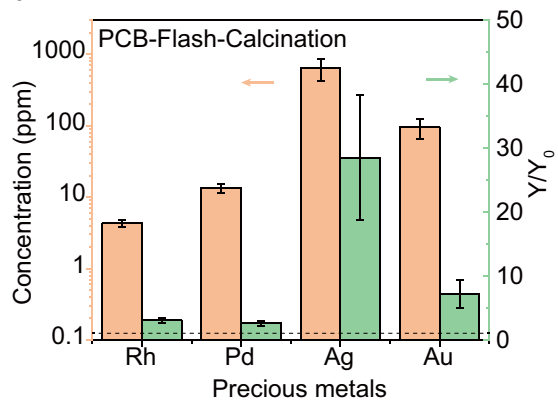

f

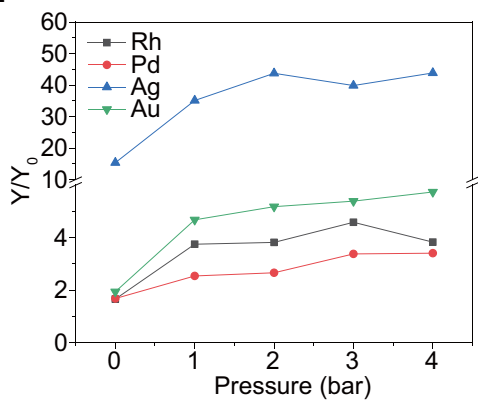

Fig. 3 Leaching efficiency improvement of precious metals by the flash Joule heating (FJH) process. a Schematic of the pressurized setup for FJH. $\mathbf{b}$ Gas flow simulation under different pressures. The inner pressure $\left(P_{0}\right)$ during the $\mathrm{FJH}$ was calculated to be $\sim 5 \mathrm{~atm}$. $P_{\text {out }}$ of 0 atm, $1 \mathrm{~atm}$, and 4 atm correspond to the $\mathrm{FJH}$ under vacuum, atmospheric pressure, and $3 \mathrm{~atm}$ of positive pressure. c Concentration of precious metals and improvement of recovery yield by $\mathrm{FJH} . Y_{0}$ and $Y$ mean the recovery yield by leaching printed circuit board (PCB) and PCB-Flash, respectively. The dashed line denotes $Y / Y_{0}=1$. The error bars denote the standard deviation where $n=3$. d Concentration of precious metals and improvement of recovery yield by FJH and calcination. $Y_{0}$ and $Y$ mean the recovery yield by leaching PCB and PCB-Flash-Calcination, respectively. The dashed line denotes $Y / Y_{0}=1$. The error bars denote the standard deviation where $n=3$. e Improvement of recovery yield varied with $\mathrm{FJH}$ voltages under atmospheric pressure. The highlighted region is the approximate optimal voltage for all metal recovery. $\mathbf{f}$ Improvement of recovery yield varied with pressure. For $\mathbf{e}$ and $\mathbf{f}$, the recovery yields of $\mathrm{Rh}, \mathrm{Pd}$, and $\mathrm{Ag}$ are calculated from PCB-Flash, and the recovery yield of Au is calculated from PCB-Flash-Calcination.

Fig. 17b). The PCB raw materials were also calcined as a control (denoted as PCB-Calcination, Supplementary Fig. 17c). The XPS analysis showed the efficient removal of carbon by calcination (Supplementary Fig. 17d). With the FJH and calcination process, the recovery yields of $\mathrm{Rh}, \mathrm{Pd}, \mathrm{Ag}$, and $\mathrm{Au}$ were increased by $3.11 \pm 0.37,2.64 \pm 0.39,28.5 \pm 9.8,7.24 \pm 2.22$ times, respectively (Fig. 3d). The values are larger than those achieved with the calcination-only process (Supplementary Figs. 17e, f).

The presumable mechanism of the improved leaching efficiency by FJH is shown in Supplementary Fig. 19. Modern electronics are fabricated and packaged by a planar process and have a laminated configuration, where the useful metals are embedded into the polymer or ceramic matrices (Supplementary Fig. 19a $)^{13}$. Even after the pulverization, the particle size was large $\sim 5 \mu \mathrm{m}$ (Supplementary Fig. 19b). The laminated structure hinders the extraction of metals in a typical hydrochemical process, resulting in elongated leaching times and low leaching efficiencies $^{13}$. During the FJH process, the matrix was rendered as an ultrafine powder at the ultrahigh temperature (Supplementary Figs. 19c, d), and the metals were exposed (Supplementary Fig. 19e), which greatly accelerated the leaching rate and extent of metal extraction.

The effects of the FJH voltage and pressure on the recovery yield were studied. It was found that the modest $\mathrm{FJH}$ voltages between 30 and $50 \mathrm{~V}$ led to the best recovery yield (Fig. 3e). Too low voltage did not provide enough energy to thermally decompose the matrix, while too high voltage presumably resulted in the evaporative loss. It was found that a higher surrounding pressure was beneficial (Fig. 3f). This is because the volatile components were trapped in the residual solid, as we projected by the gas- flow simulations (Fig. 3b). The mild acidleaching condition $\left(1 \mathrm{M} \mathrm{HCl}, 1 \mathrm{M} \mathrm{HNO}_{3}\right)$ used in our process is more cost-effective and environmentally friendly compared to other hydrometallurgical processes, which use highly concentrated mineral acids such as aqua regia ${ }^{13,29}$, or toxic cyanides ${ }^{18,30}$ as extractants for achieving a high-recovery yield. 
a
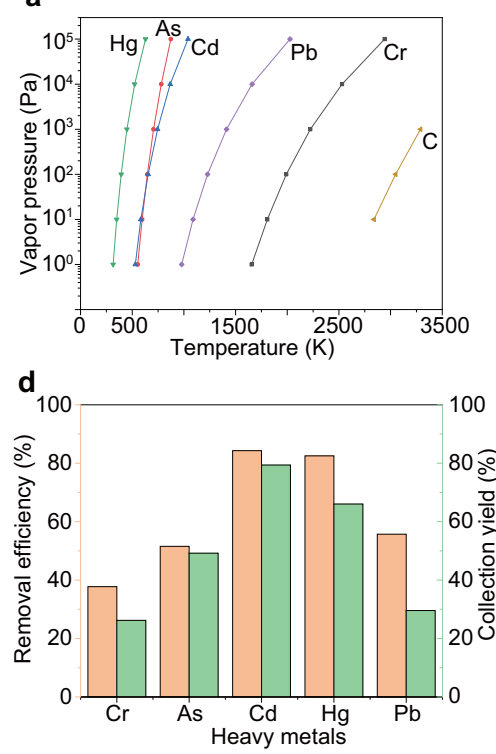

b

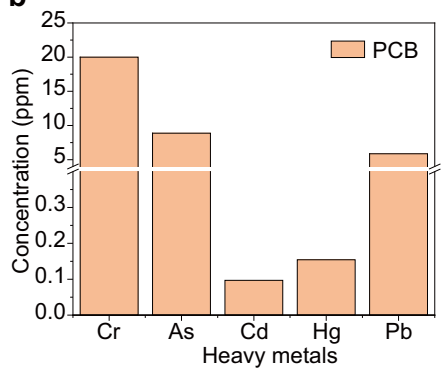

e

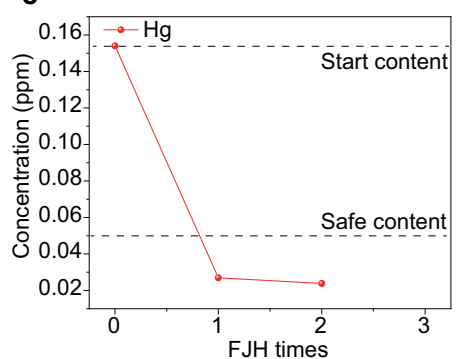

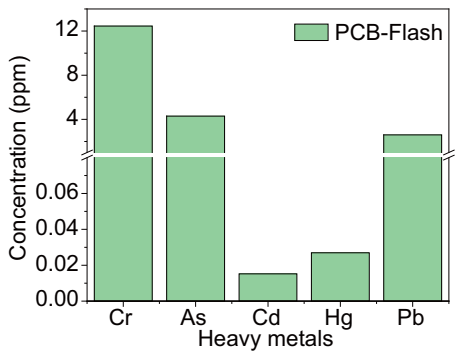

f

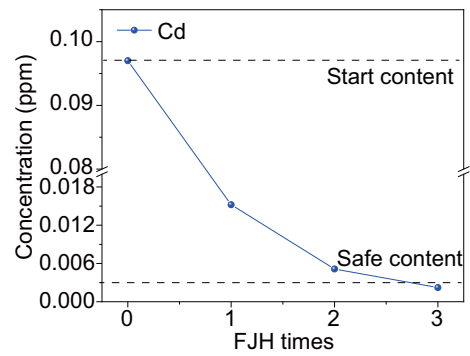

Fig. 4 Removal of heavy metals in e-waste by flash Joule heating (FJH) process. a Vapor pressure-temperature relationships of toxic heavy metals and carbon. b Concentrations of toxic heavy metals in the printed circuit board (PCB). c Concentrations of toxic heavy metals in PCB after FJH. d Removal efficiency and collection yield of heavy metals. The efficiency and yield were the average of three independent FJH experiments $(n=3)$. e Concentration of $\mathrm{Hg}$ in the residues after multiple $\mathrm{FJH}$ reactions. $\mathbf{f}$ Concentration of $\mathrm{Cd}$ in the residues after multiple FJH reactions. The dashed lines in (e, $\mathbf{f}$ ) represent the starting contents and the approved World Health Organization (WHO) level for safe limits of agricultural soils.

Removal and collection of toxic heavy metals in e-waste. Removal of toxic components is another major concern for e-waste processing 3,6,7,31. The heavy metal removal capability of the $\mathrm{FJH}$ process was evaluated. Compared to precious metals, heavy metals, including $\mathrm{Cr}, \mathrm{Pb}, \mathrm{Cd}, \mathrm{As}$, and $\mathrm{Hg}$, have much higher vapor pressures and lower boiling points (Fig. 4a and Supplementary Fig. 7b). Especially for the most toxic $\mathrm{Cd}$, As, and $\mathrm{Hg}$, the separation factors between them and precious metals could achieve $\sim 10^{5}$ based on the theoretical analysis (Supplementary Note 4). The levels of heavy metals in PCB waste are in the range of $0.1-20$ ppm (Fig. 4b). These values are above the safe limits of heavy metals in soils for agriculture as recommended by the world health organization $(\mathrm{WHO})^{32}$. After one $\mathrm{FJH}$, the heavy metal contents in the remaining solid (PCBFlash) were greatly reduced (Fig. 4c). The removal efficiencies of $\mathrm{Hg}$ and $\mathrm{Cd}$ were calculated to be $>80 \%$, followed by $\mathrm{Pb}$ and $\mathrm{As}(>50 \%)$, and $\mathrm{Cr}(>35 \%)$ (Fig. $4 \mathrm{~d}$ and Supplementary Note 2). These efficiencies were consistent with their vapor pressure values (Fig. 4a). The heavy metals were collected by condensation in the cold trap, as we did for the evaporative separation, and the collection yields were calculated (Fig. 4d). The collection yield matched well with the removal efficiency, demonstrating that most of the evaporated heavy metal was trapped by the cold trap, minimizing the leakage of heavy metals into the environment during the recycling process.

The concentration of heavy metals in the residue solids could be further reduced by multiple $\mathrm{FJH}$ reactions. After one $\mathrm{FJH}$ reaction, the concentration of $\mathrm{Hg}$ was reduced to below the safe limit of $\mathrm{Hg}$ in soils for agriculture $(0.05 \mathrm{ppm})(\text { Fig. } 4 \mathrm{e})^{32}$, the highest standard for waste disposal. As for $\mathrm{Cd}$, three consecutive FJH cycles reduced the concentration to below the safe limit $(0.003 \mathrm{ppm})$ (Fig. $4 \mathrm{f})^{32}$. The concentration of $\mathrm{As}, \mathrm{Pb}$, and $\mathrm{Cr}$ were all reduced with an increase in the number of $\mathrm{FJH}$ reactions (Supplementary Fig. 20). Since each FJH only takes $1 \mathrm{~s}$, multiple flashes are easily accomplished.

\section{Discussion}

The proposed evaporative separation scheme is mainly targeted to the recovery of metals from e-waste. Nevertheless, it could exhibit the capability for the separation of metals. Theoretical calculation shows that large separation factors up to $\sim 10^{5}$ could be realized for most metals with large vapor pressure differences (Supplementary Note 4, theoretical separation factors of the evaporative separation process based on the vapor pressure difference, Supplementary Fig. 21, Supplementary Table 3). The theoretical separation factors are calculated based on the vapor pressure of pure metals. They represent practical values for trace metal separation even with the melt alloy formation (Supplementary Note 4, the effect of melt alloy formation on the separation factors, Supplementary Fig. 22). The different recovery yields of precious metals (Fig. 1g) already demonstrated the separation feasibility of the FJH process based on the vapor pressure difference (Supplementary Note 4, the achieved separation ability by the evaporative separation, Supplementary Table 4). The chemical additives (Fig. 2a-f) also regulated the precious metals separation presumably due to their different chemical reactivity (Supplementary Note 4, the metal separation ability from the chemical additives, Supplementary Tables 5-7). The separation ability of the evaporative separation scheme could be further improved by progressively increasing the FJH temperature (Supplementary Note 4, the evidence-based predictions on the practices to increase the separation factors).

The cost and benefit of the FJH processing were evaluated since economic incentives are the main driver for waste recycling (Supplementary Note 5$)^{8}$. FJH is a highly efficient heating process due to the ultrafast heating/cooling rate, the direct sample heating feature, and the short reaction duration, compared to traditional smelting furnaces where large amounts of energy are used to maintain the temperature of the whole chamber ${ }^{33}$. The FJH method has an energy consumption of $\sim 939 \mathrm{kWh} \mathrm{ton}^{-1}$, which is $\sim 1 / 500$ of that for a labscale tubular furnace ${ }^{34}$, and $\sim 1 / 80$ of that for a commercially used Kaldo furnace in industrial scale ${ }^{35}$ (Supplementary Note 5). Hence, the $\mathrm{FJH}$ process for e-waste processing could have advantages over traditional pyrometallurgical processes.

The FJH process is scalable. According to the scaling rule revealed by the theoretical analysis, we could increase the $\mathrm{FJH}$ 
voltage and/or the capacitance of the capacitor bank when scaling up the sample mass (Supplementary Note 6 and Supplementary Figs. 23 and 24). By using a homemade automation system integrated with the FJH setup, our research lab has already realized a production rate of $>10 \mathrm{~kg} \mathrm{day}^{-1}$. Further commercial scaling up of the FJH process is underway (Supplementary Note 6). Considering the diminishing easily accessible ores of precious metals and the toxicity of several metal elements, the proposed FJH process to recover metals in e-waste could be a harbinger for near-future recovery methods.

\section{Methods}

Materials. CB (Cabot, Black Pearls 2000, average diameter $10 \mathrm{~nm}$ ) was used as the conductive additive. The PCB waste was from a discarded computer. The PCB was cut into small pieces using a saw, and then ground into microscale powders by using a hammer grinder (Dade, DF-15). The salt additives were $\mathrm{NaCl}$ (J.T. Baker), $\mathrm{NaF}$ (Acros Organics), and NaI (Aldrich, 99.5\%). The precious metals chlorides were $\mathrm{RhCl}_{3}$ (Aldrich, 38-40\% Rh), $\mathrm{PdCl}_{2}$ (Aldrich, 99\%), $\mathrm{AgCl}$ (Allied Chemical), and $\mathrm{AuCl}_{3}$ (Aldrich, >99.9\%). Polytetrafluoroethylene (PTFE) powder was purchased from Runaway Bike. PVC, CPVC, and polyvinylidene fluoride (PVDF) plastic tubes from plumbing pipes were used as raw materials. The plastic waste products were cut into small pieces using a saw, and then ground into powders by using a hammer grinder (Dade, DF-15).

FJH system and evaporative separation process. The electrical diagram of the FJH reactor is shown in Supplementary Fig. 3. There is a risk of electrocution so all safety measures should be obeyed carefully, as we listed in detail in the Supplementary Information. CB, PCB powders, and additives were mixed by using ball milling (MSE Supplies, PMV1-0.4 L). The reactants were loaded into a quartz tube with an inner diameter of $8 \mathrm{~mm}$ and an outer diameter of $12 \mathrm{~mm}$. Copper wool was used as the porous electrode on one side to facilitate the gas diffusion, and a graphite rod was used as the electrode on the other side of the quartz tube. The tube was then loaded on the reaction stage and connected to the FJH system. The resistance was controlled by compressing the electrodes. The quartz tube was sealed by an O-ring. A vessel with a volume of $\sim 40 \mathrm{~mL}$ was used as the cold trap. The vessel should withstand negative pressure $(\sim 10 \mathrm{~Pa})$. A mechanical pump was used to pump the vessel to vacuum; then, the trap was immersed into the liquid $\mathrm{N}_{2}$ Dewar. This sequence must be followed to avoid $\mathrm{O}_{2}$ condensation in the $\mathrm{N}_{2}$ Dewar since $\mathrm{O}_{2}$ has a higher boiling point than $\mathrm{N}_{2}$. A capacitor bank with a total capacitance of $60 \mathrm{mF}$ was charged by a direct current (DC) supply that can reach voltages up to $400 \mathrm{~V}$. A relay with programmable ms-level delay time was used to control the discharge time. The high-voltage discharging brings the sample to a high temperature. The detailed conditions for the FJH are listed in Supplementary Table 1. For each condition, three FJH experiments were conducted to collect the total volatiles for sample digestion and ICP-MS measurement. Hence, the measured recovery yield is the average of three independent experiments using the same circuit board. After the FJH reaction, the $\mathrm{FJH}$ apparatus was allowed to cool to room temperature while the cold trap remained immersed in the liquid $\mathrm{N}_{2}$. Then, the trap was taken out from the liquid $\mathrm{N}_{2}$ while the apparatus remained under vacuum. After the trap warmed to room temperature, the vacuum was released.

FJH under atmospheric and positive pressure. The $\mathrm{FJH}$ reaction is similar to the evaporative separation except with the following changes. The quartz tube was sealed by an O-ring to hold pressure. The porous $\mathrm{Cu}$ electrode side was connected to an inner gas $\left(\mathrm{N}_{2}\right)$ cylinder by tubing that withstands pressure up to 5 bar. The pressure was adjusted to the desired values (1-4 atm) using a regulator and was monitored by a pressure gauge. Once the pressure was set, the FJH system was charged and then discharged for reaction. The detailed conditions for the FJH are shown in Supplementary Table 2. After the FJH reaction, the pressure was released, and the sample was removed for further analysis.

Characterization. The SEM images were obtained by using a FEI Helios NanoLab 660 DualBeam SEM system at $5 \mathrm{kV}$. XRD was collected by using a Rigaku D/Max Ultima II system configured with a $\mathrm{Cu} \mathrm{Ka}$ radiation $(\lambda=1.5406 \AA)$. XPS spectra were taken using a PHI Quantera XPS system under the base pressure of $5 \times 10^{-9}$ Torr. Elemental XPS spectra were collected using a step size of $0.1 \mathrm{eV}$ with a pass energy of $26 \mathrm{eV}$. All of the XPS spectra were calibrated by using the standard $\mathrm{C} 1 s$ peak at $284.8 \mathrm{eV}$. STEM images and EDS maps were taken on a JEOL 2100 Field Emission Gun Transmission Electron Microscope under the voltage of $200 \mathrm{kV}$. TGA was conducted in air at a heating rate of $10^{\circ} \mathrm{C} \mathrm{min}^{-1}$ up to $1000^{\circ} \mathrm{C}$ by using a Q-600 Simultaneous TGA/DSC from TA instruments. Calcination was conducted using the Mafu furnace in the air (NEY 6-160 A).

Sample digestion and ICP-MS measurement. The standards were purchased from Millipore-Sigma. Three periodic table mixtures and $\mathrm{Hg}$ standard were used, where the composition is listed in Supplementary Table 8. $\mathrm{HNO}_{3}$ (67-70 wt\%, TraceMetal ${ }^{\mathrm{TM}}$ Grade, Fisher Chemical), $\mathrm{HCl}$ (37 wt\%, $99.99 \%$ trace metals basis, Millipore-Sigma), and water (Millipore-Sigma, ACS reagent for ultratrace analysis) were used for sample digestion. The samples were digested by using a diluted aqua regia method ${ }^{14,19}$. The samples were soaked in $\mathrm{HNO}_{3} / \mathrm{HCl}(1 \mathrm{M}$ each) solution at $45^{\circ} \mathrm{C}$ for $24 \mathrm{~h}$. The acidic solution was filtered to remove any undissolved particles. The solution was then diluted to the appropriate concentration range using $2 \mathrm{wt} \%$ $\mathrm{HNO}_{3}$ or $\mathrm{HCl}$ within the calibration curve. ICP-MS was conducted using a Perkin Elmer Nexion 300 ICP-MS system. The PCB raw powder, the condensed solid from the cold trap, the PCB-Flash powder, the PCB-Flash-Calcination powder, and the PCB-Calcination powder were leached using the same protocol.

\section{Data availability}

The data supporting the findings of this study are available within the article and its Supplementary Information. Other relevant data are available from the corresponding author upon reasonable request. Source data generated in this study are provided in the Source Data file. The Source Data file is also uploaded to the Zenodo repository https:// doi.org/10.5281/zenodo.5293916. Source data are provided with this paper.

Received: 4 May 2021; Accepted: 7 September 2021; Published online: 04 October 2021

\section{References}

1. Zhang, K., Schnoor, J. L. \& Zeng, E. Y. E-waste recycling: where does it go from here? Environ. Sci. Technol. 46, 10861-10867 (2012).

2. Zeng, X. L., Mathews, J. A. \& Li, J. H. Urban mining of e-waste is becoming more cost-effective than virgin mining. Environ. Sci. Technol. 52, 4835-4841 (2018).

3. Ogunseitan, O. A., Schoenung, J. M., Saphores, J.-D. M. \& Shapiro, A. A. The electronics revolution: From e-wonderland to e-wasteland. Science 326, 670-671 (2009).

4. Wang, Z. H., Zhang, B. \& Guan, D. B. Take responsibility for electronic-waste disposal. Nature 536, 23-25 (2016).

5. Ghosh, B., Ghosh, M. K., Parhi, P., Mukherjee, P. S. \& Mishra, B. K. Waste printed circuit boards recycling: an extensive assessment of current status. J. Clean. Prod. 94, 5-19 (2015).

6. Leung, A. O. W., Duzgoren-Aydin, N. S., Cheung, K. C. \& Wong, M. H. Heavy metals concentrations of surface dust from e-waste recycling and its human health implications in southeast China. Environ. Sci. Technol. 42, 2674-2680 (2008).

7. Julander, A. et al. Formal recycling of e-waste leads to increased exposure to toxic metals: an occupational exposure study from Sweden. Environ. Int. 73, 243-251 (2014)

8. Awasthi, A. K., Li, J. H., Koh, L. \& Ogunseitan, O. A. Circular economy and electronic waste. Nat. Electron. 2, 86-89 (2019).

9. Kaya, M. Recovery of metals and nonmetals from electronic waste by physical and chemical recycling processes. Waste Manag. 57, 64-90 (2016).

10. Popoola, O. E., Popoola, A. O. \& Purchase, D. Levels of awareness and concentrations of heavy metals in the blood of electronic waste scavengers in Nigeria. J. Health Pollut. 9, 190311 (2019).

11. Hall, W. J. \& Williams, P. T. Separation and recovery of materials from scrap printed circuit boards. Resour. Conserv. Recy. 51, 691-709 (2007).

12. Cui, J. R. \& Zhang, L. F. Metallurgical recovery of metals from electronic waste: a review. J. Hazard. Mater. 158, 228-256 (2008).

13. Sun, Z. et al. Toward sustainability for recovery of critical metals from electronic waste: the hydrochemistry processes. ACS Sustain. Chem. Eng. 5, $21-40$ (2017)

14. Jadhav, U. \& Hocheng, H. C. Hydrometallurgical recovery of metals from large printed circuit board pieces. Sci. Rep. 5, 14574 (2015).

15. Zhuang, W. Q. et al. Recovery of critical metals using biometallurgy. Curr. Opin. Biotech. 33, 327-335 (2015).

16. Sarvar, M., Salarirad, M. M. \& Shabani, M. A. Characterization and mechanical separation of metals from computer printed circuit boards (PCBs) based on mineral processing methods. Waste Manag. 45, 246-257 (2015).

17. Yamane, L. H., de Moraes, V. T., Espinosa, D. C. R. \& Tenorio, J. A. S. Recycling of WEEE: characterization of spent printed circuit boards from mobile phones and computers. Waste Manag. 31, 2553-2558 (2011).

18. Sethurajan, M. et al. Recent advances on hydrometallurgical recovery of critical and precious elements from end of life electronic wastes-a review. Crit. Rev. Env. Sci. Tec. 49, 212-275 (2019).

19. Hong, Y. et al. Precious metal recovery from electronic waste by a porous porphyrin polymer. Proc. Natl Acad. Sci. USA 117, 16174-16180 (2020).

20. Abrahamson, J. Graphite sublimation temperatures, carbon arcs and crystalline erosion. Carbon 12, 111-141 (1974). 
21. Luong, D. X. et al. Gram-scale bottom-up flash graphene synthesis. Nature 577, 647-651 (2020).

22. Algozeeb, W. A. et al. Flash graphene from plastic waste. ACS Nano 14, 15595-15604 (2020).

23. Okamoto, H., Schlesinger, M. E. \& Mueller, E. M. ASM Handbook Volume 3: Alloy Phase Diagrams. (ASM International, 2016).

24. Lide, D. R. CRC Handbook of Chemistry and Physics, Ch. 4 (CRC Press, Internet Version, 2005).

25. Pearson, R. G. Hard and soft acids and bases. J. Am. Chem. Soc. 85, 3533-3539 (1963).

26. Ueda, T., Ichiishi, S., Okuda, A. \& Matsutani, K. Metal Sustainability: Global Challenges, Consequences, and Prospects, Ch. 15 (John Wiley \& Sons Press, 2016).

27. Yao, Y. G. et al. Carbothermal shock synthesis of high-entropy-alloy nanoparticles. Science 359, 1489-1494 (2018).

28. Olavarria-Contreras, I. J. et al. C-Au covalently bonded molecular junctions using nonprotected alkynyl anchoring groups. J. Am. Chem. Soc. 138, 8465-8469 (2016).

29. Park, Y. J. \& Fray, D. J. Recovery of high purity precious metals from printed circuit boards. J. Hazard. Mater. 164, 1152-1158 (2009).

30. Quinet, P., Proost, J. \& Van Lierde, A. Recovery of precious metals from electronic scrap by hydrometallurgical processing routes. Miner. Metall. Proc. 22, 17-22 (2005)

31. Sun, G. L., Reynolds, E. E. \& Belcher, A. M. Using yeast to sustainably remediate and extract heavy metals from waste waters. Nat. Sustain. $\mathbf{3}$ 303-311 (2020).

32. Kinuthia, G. K. et al. Levels of heavy metals in wastewater and soil samples from open drainage channels in Nairobi, Kenya: community health implication. Sci. Rep. 10, 8434 (2020).

33. Khaliq, A., Rhamdhani, M. A., Brooks, G. \& Masood, S. Metal extraction processes for electronic waste and existing industrial routes: a review and Australian perspective. Resources 3, 152-179 (2014).

34. Balaji, R. \& Senophiyah-Mary, J. Urban Mining and Sustainable Waste Management, Ch. 7 (Springer, 2020).

35. Theo, L. Integrated recycling of non-ferrous metals at Boliden Ltd. Ronnskar smelter. in Proceedings of the 1998 IEEE International Symposium on Electronics and the Environment. ISEE - 1998 (Cat. No. 98CH36145) 42-47 (IEEE, 1998)

\section{Acknowledgements}

We acknowledge Dr. Helge Gonnermann of Rice University for allowing us to use the FEM simulation software. We acknowledge Dr. Bo Chen of Rice University for the

helpful discussion of the XPS results. The funding of the research is provided by the Air Force Office of Scientific Research (FA9550-19-1-0296) and the Department of Energy, DOE-NETL (DE-FE0031794). The authors acknowledge the use of the Electron Microscopy Center (EMC) at Rice University. This work was conducted in part using resources of the Shared Equipment Authority (SEA) at Rice University.

\section{Author contributions}

B.D. and J.M.T. conceived the idea to use FJH to recover metals. B.D. conducted most of the experimental work with the help of Z.W., E.A.M. helped with the ICP-MS, and C.K. and D.X.L. designed and built the FJH system and the temperature measurement setup. B.D. and J.M.T. wrote the manuscript. All aspects of the research were overseen by J.M.T. All authors discussed the results and commented on the manuscript.

\section{Competing interests}

Rice University owns intellectual property on the $\mathrm{FJH}$ strategy for urban mining, and a patent application has been filed. The scaling of the $\mathrm{FJH}$ process for the production of graphene (not considered in the research described here) is licensed by Universal Matter Inc. and Universal Matter Ltd. from Rice University. J.M.T. owns stock in these companies, but he is not an officer or director therein. All conflicts of interest are managed through regular disclosure to the Rice University Office of Sponsored Programs and Research Compliance.

\section{Additional information}

Supplementary information The online version contains supplementary material available at https://doi.org/10.1038/s41467-021-26038-9.

Correspondence and requests for materials should be addressed to James $\mathrm{M}$. Tour.

Peer review information Nature Communications thanks the anonymous reviewer(s) for their contribution to the peer review of this work.

Reprints and permission information is available at http://www.nature.com/reprints

Publisher's note Springer Nature remains neutral with regard to jurisdictional claims in published maps and institutional affiliations.

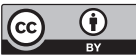

Open Access This article is licensed under a Creative Commons Attribution 4.0 International License, which permits use, sharing, adaptation, distribution and reproduction in any medium or format, as long as you give appropriate credit to the original author(s) and the source, provide a link to the Creative Commons license, and indicate if changes were made. The images or other third party material in this article are included in the article's Creative Commons license, unless indicated otherwise in a credit line to the material. If material is not included in the article's Creative Commons license and your intended use is not permitted by statutory regulation or exceeds the permitted use, you will need to obtain permission directly from the copyright holder. To view a copy of this license, visit http://creativecommons.org/ licenses/by/4.0/

(c) The Author(s) 2021 